\title{
Hyper-Leading in an era of Hyper-Change
}

\author{
Dr. Linda Ellington \\ Professor of Business, Southern New Hampshire University, Manchester, USA
}

*Correspondence: Dr. Linda Ellington, 1.ellington@snhu.edu

\begin{abstract}
It is change, continuing change, inevitable change that is the dominant factor in society today. No sensible decision can be made any longer without considering not only the world as it is, but the world as it will be. One of the key challenges for future leaders is to effectively and constructively lead change that is taking place both within organizations and in the broader social and political spheres. It is not past patterns of change that matter, it is that the nature of change is changing. As hyper-change alters the governing domain, leaders will be forced to change the ways they govern and lead - enter hyper-leaders.

This article was written with three goals in mind: 1) to introduce strategies for an emerging style of leader; one who realizes that leadership is on the line and who must survive and thrive through the dangers of change, 2) to respond to a sansdemic drought, 3) to take notice of opportunities that act as accelerants to change which simply speed up the effects of a more nefarious and longterm volatile world.
\end{abstract}

Keywords: Hyper-Leading, Hyper-Change, Sansdemic drought, Screenagers, Leadership disruption, Humanocracy, Design thinking, Adaptive leading, Growth-Mindset

\section{ARTICLE INFORMATION}

Author(s): Dr. Linda Ellington

Received: 06 June, 2021; Accepted: 12 July, 2021 Published: 30 July, 2021 e-ISSN: 2347-4696;

Paper Id: BMN-IJBMR-2021-48;

Citation: doi.org/10.37391/IJBMR.090304

Webpage-link:

https://ijbmr.forexjournal.co.in/archive/volume-9/ijbmr-090304.html

\section{LEADERSHIP ON THE LINE}

To lead is to live dangerously. It's romantic and exciting to think of leadership as all inspiration, decisive action, and rich rewards, but leading requires taking risks that can jeopardize your career and your personal life. It requires putting yourself on the line, disrupting the status quo, and surfacing hidden conflict. And when people resist and push back, there's a strong temptation to play it safe. Those who choose to lead plunge in, take the risks, and sometimes get burned.

But it doesn't have to be that way say renowned leadership experts Ronald Heifetz and Marty Linsky. In Leadership on the Line, they show how it's possible to make a difference without getting "taken out" or pushed aside. They give equal weight to the dangerous work of leading change and navigating the perilous straits of leadership. They posit that a change begins with an idea, perhaps a best practice, with little respect for the soil in which it must take root. Even if it is on paper a great idea the importance of the idea risks uprooting more than it should, disorienting and disvaluing people more than is needed, and in the end often a cultural immune reaction that rejects or distorts the original idea regardless of one's intentions [1].

The global turmoil, whether it be a pandemic of galactic size, a political upheaval, an economic crisis, or even a seismic shift in the technology, hyper-challenges are shifting the role of leadership as we know it. To reimagine how to lead in this hyper-change era one must incorporate four topics into the conversation: reality, relevancy, rethinking, and reimagining. The shadow side of not paying attention to those four objectives causes leaders to fruitlessly waste time and money by focusing on superficial skills and abilities thus, not surviving nor thriving.

To illustrate the thinking behind the major drivers causing hyper-change one only needs to conjure up a dystopian version of reality. Literature describes the themes of a dystopian viewpoint of what might happen to the world: society rebellion, political oppression, revolutions, wars, and climate disasters [2]. Keep in mind that the opposite is utopia, which is not reality, yet many leaders still use that mindset to lead, which is irrelevant in today's global chaos.

The right leaders will undoubtedly emerge and so the question is, what form will these leaders take? First, leaders need to develop new strategies for internal mobility, reskilling, and job redeployment which are among the most important innovations at work. Second, leaders are to become open to part-time workers, employees who live and work remotely, and workers who need training to perform [3]. This will require leaders to deal with a threshold handicap they must overcome which is the inertia of 'it has always been thus' - a syndrome that too often fools leaders in any enterprise [2]. Now one might ask, how does a leader shrug off that syndrome to successfully lead through change that appears to be on steroids? The simple answer is right in front of us; however, do not use the utopia lens to see, but rather the realistic lens. Redefining what it means to lead is constantly being redefined and is more acute than ever before [4]. The current world context is responsible for the dark side of such a global stage; growing inequality, unemployment, underemployment, and increased global mobility due to forced migration. Thus, these challenges have created dynamic and 
complex changes that are introducing challenges for those who dare to lead $[5,6]$. This will also challenge leaders to get their myopia corrected; meaning facing any disruptive issue with a broader view and broaden participation by others [2].

As the world faces uncertainty leaders are faced with the challenge of responding to hyper change. It seems like every day, if not every hour, decisions out of our control are being made that influence how we work, how we live, and how we interact with others. Change is challenging to address, especially when we don't have information about three key factors:

- Timing/pace of change

- Scope of change

- Impact of change

This lack of information can result in hesitancy and even panic during a time when organizational leaders need to lead with a wider lens than previously - considering that the visual will expand into leaders clearly seeing the critical success factor is diversity.

\section{DIVERSITY}

The importance of diversity is to stop the stampede toward a single, homogeneous model of leadership. Iger [7] posited from his 15 years as CEO of the Walt Disney Company, that diversity is critical to the success of an organization, which means leaders must build a culture of trust based on the brilliance of diversity, fuel a deep and abiding curiosity throughout the organization when facing hyper-changes that are difficult to face (p. xxvi).

Cultural diversity is a powerful springboard for the construction of building an organization that encompasses the uniqueness of each individual across a wide spectrum [8]. This is a critical success factor for hyper-leaders to take notice in pursuing a diversity-rich future; a leadership talent allowing for a completely new thought perspective. Simply stated the world is not comprehensible, but it is embraceable; through the embracing of one of its beings [9].

In her book, Dare to Lead, Brown [6] challenged leaders to step up to the ideas of daring greatness through diversity, rising strong and braving the wild unknown, escalating into being change makers, culture shifters and creative beings. One must lead with intentionality in reimaging and re-engineering their leadership practices and welcome the fact that peoplecentric organizations tend to come up with many different associations, as least of which are idiosyncratic and possibly uniqueness which builds into the idea of humanocracy. Even as we look back into history Tolle told us that the mind gives form to the creative impulse or insight and even the greatest scientists have reported that creativity is a result of leaders and followers who do not know how to stop thinking [10]. One might ask, is there creativity in madness?

\section{CREATIVITY THROUGH HYPER- LEADING}

Drawing on more than a decade of research, Hamel and Zanini [11] noted when leaders run out of patience with bureaucracy and if a leader wants to build an organization that can outrun change and is committed to giving every team member the chance to learn, grow and contribute, then the unstoppable movement to create an organization that is fit for the future and fit for human beings will be reality. Hardiman [12] noted that creativity is a hallmark of 21 st century people skills. He stated, "The brain processes information when people are engaged in creative tasks, as opposed to ordinary activities that depend on rote knowledge" (p.15).

According to Gardner [13] leaders should inspire creativity throughout the organization. However, like intelligence, the term creativity has been applied over the years as an honorific label to a wide range of individuals and situations. But as happened with the term intelligence, it is necessary to shift from the individual mind to the broader idea of distributed sociocultural bases of intelligence that then extends the nature of creativity where people tend to come up with many different associations in solving problems $[14,15]$. Hamel and Zanini described this phenomenon as humanocracy [11]. One might explore future research that may be able to develop a theory, and thus identify competencies of a humanocractic leader.

Through the practices of humanocracy, the time to dismantle bureaucracy effectively, passionately, and comprehensively is now; and how this is done is to reimagine leadership abilities that can revitalize organizations - thus, the hyper-leader enters. Hamel and Zanini issued a stirring call for leaders to do better - to build organizations that liberate the everyday genius of the people inside the organization. Be the leader who infuses the spirit of creativity and a growth mindset that inspires the future organization; be the leader who replaces chain of command with chain of trust and radical transparency; be the leader who unlocks game-changing innovation $[11,16,17]$. Be the leader who can identify and achieve the right goals for the organizations and communities they serve. This is needed now more than ever, especially at the micro and macro levels of leadership.

Micro level is when workers are pressured by the move to a shared economy, the untethering of work from a physical location, the displacement of human labor by technology and growing demands for diversity, inclusion, and belonging [18]. As employment status shifts from gainful employment by a company to multiple independent and less secure worker modalities, employees are forced to change careers due to (in)voluntary disruptions or setbacks, constantly needing to recreate themselves, and build a greater resilience into their career journey.

Macro level is societal which is already strained and threatened by the global risk context. The strains are due to demographic pressures, fear of robotics and artificial intelligence supplanting many low and mid-tier jobs, the 
lingering impact of the global economic downturn, the mass migration of labor, the hollowing out of work, and growing income inequality [18].

Based on Claus [5] and Hess's [19] call for action a leader needs to turn dead end jobs into get-ahead jobs - which is possible if the leader treats every person and their respective role as indispensable to collective success. Hess stated, "A symphony of synchronicity is, quite simply, beautiful. One cannot help but be impressed by what human beings can accomplish when they work in concert" [19].

Thus, the call to action is:

- Humanize the workplace to optimize the power of human cognitive, emotional, and behavioral performance individually and organizationally [11].

- Create an environment to think differently [20].

- Foster intrapreneurial thinkers within the organization [21].

- Make decisions in environments with lots of uncertainty and little data; and connect with other human beings through high emotional engagement and collaboration $[13,19]$.

- Preserve a mental balance in unfamiliar situations.

Be the leader who has the talent and courage to create an organization that is not brittle and not backward-looking. This type of leadership pessimistic view would be justified except for one salient fact:

As human beings we are resilient, inventive, and exuberant. The fact that organizations are not suggests that in some important ways, the organizations are less human than we are. Ironically, it seems that human-build organizations have scant room for exactly those things that make us furless bipeds special - things like courage, intuition, love, playfulness, and artistry [11]

It would behoove us to pay attention to a different way of viewing our organizations. Dweck [17], Collins [22], and Hess [19] told us to shift to a growth-mindset concept because that way of rethinking has the power to motivate those we lead, to transform organizations, and to inspire followers to want to follow us.

The edited work of Sowick (Leadership 2050), supported the notion that challenges of leadership are growing and not shrinking. It would benefit leaders to read Mack's chapter, Leadership in the Future in Sowick's edited book [23] in which he stated, "I will propose at the outset that the future of leadership is the future of humanity and when thinking about what is relevant in leadership, it is difficult not to respond, 'what is not?' [23].

\section{\% 4. A HYPER-LEADER EMBRACES DESIGN THINKING}

According to Siang [24] design thinking is a non-linear, iterative process that teams use to understand users, challenge assumptions, redefine problems and create innovative solutions. It is about the principles of designing to the way people work [25]. This type of thinking uses mainly abductive reasoning - namely to conjecture what could possibly be true, actively look for data points, and challenge accepted explanations and to infer possible new worlds [26].

One of the hallmarks of a design thinker is being able to reduce unnecessary workplace complexity [27]. Craig [2] quoted John Ruskin, a Victorian artist who stated "It is far more difficult to be simple than to be complicated; far more difficult to sacrifice skill and easy execution in the proper place than to expand both indiscriminately [2]. A designcentric concept creates models to examine complex problems in the workplace, uses prototypes to explore potential solutions, and tolerates failure. Thus, a new leadership talent is evolving centering on needed societal interventions, shared responsibility, and coordination at various levels----once again the hyper-leader enters.

Hess [19], Hardiman [12] and Dweck [17] agreed that changing leadership behaviors requires changing our way of being - our internal story of who we are and how the world works. Hess noted that before we can enable ourselves to become hyper-leaders, we need to create the right mindset - a story of why we should change [17]. Dweck supported this idea as documented her book, Mindset (2016) that the view that we adopt for ourselves profoundly affects the way one leads their life and leads others [17]. Thus, her philosophy called the growth-mindset, is based on the knowledge that the basic qualities of our thinking cultivate efforts, targeted strategies, and help from others. To illustrate the framework of a growth-mindset:

- $\quad$ Find challenges for you to grow.

- Seek experiences that will stretch you.

- Use the passion for stretching oneself and sticking to it, even when it is not going well.

Connecting to the cognitive aspect of hyper-leading, Hardiman noted that there is an intricate interplay between cognition and emotion. Burn \& Houston's chapter in edited book by Sowick, [23] supported Hardiman's theory as they noted that leadership capacity comes from social artistry; meaning the ability to connect by incorporating emotion and creativity. To expand on the work by Hardiman, [12] Burn and Houston, both neuroscientists continued to demonstrate differences in how the brain processes information when humans are engaged in creative, spontaneous tasks, as opposed to activities that depend on rote knowledge.

From their research and findings, they determined that leaders need to:

- Gain a new vision

- Create a workplace environment for one to know "construction zone: brains in progress." 
- Encourage everyone to do new things, not simply repeating what other generations have done.

- Foster ample opportunities to have everyone be inventive and to apply knowledge in ways that contribute to developing and fostering the creative / curious mind.

- Provide time that promotes divergent thinking thus allowing for new and distinct free-flowing thoughts.

We know that the capacity to lead, is not fixed in stone at birth as everyone has high potential to grow. We all can learn to lead no matter what our IQ score is. Let that quotient not be our obstacle or excuse for not taking bold steps into being the hyper-leader who takes their organizations to higher heights moving through the global orbit.

In characterizing an era with a specific label, one runs the risk of making a claim that cannot be substantiated. And yet, the hyper-leading label fits clearly in the 21 st century as the global planet seems to be under a strong magnetic force of uncertainty and chaos. Hyper-leaders need to be able to not only reinvent themselves but to reimagine their organizations; act decisively, never panic, communicate clear directions to the teams, solve problems creatively, and achieve the results to be the most thorough transformation [2]. Palus and Horth [28] contend that the world's volatility is a call to action for leaders to embrace adaptability, especially when leading through uncertainty and ambiguity.

\section{THE ADAPTABLE LEADER}

By not being an adaptable leader, mistakes will stem from lack of clarity about the goals and objectives of the organizational vision and direction. Mistakes created from teams who have not been empowered the freedom to explore alternatives or from teams who have not been given enough time to choose thoughtfully from the alternatives they have invented or discovered is the failure of the leader who did not consider the ramifications of making changes. Thus, an important characteristic of a hyper-leader is one who moves from hyperlearning to hyper-leading.

Heifetz and Linsky [1] set the stage for leaders who need to know that while the need for adaptability has always been critical, never has its significance been as front and center as it is today. In their writings they describe leaders who need to figure out how to adapt to the multiple daunting challenges: stateless and state-sponsored terrorism; wars, and refugees; the effects of climate change in the violence of storms, flooding the coastal cities, and drought; the dangers of new viral pandemics; population growth that exceed the carrying capacity of families and economies; the internet and social media offspring changing how human beings communicate with each other.

The adaptive challenge is the opportunity to see our current world as a new, not just the same old, or just fading gloriously off into the sunset, but as a whole new period of journey, needing to be invented, what Mary Bateson called "active wisdom" in her book, 'Composing a Further Life' [29]. She challenged leaders how to take what they think they have learned and make it available to a wider and different audience, or in a different way than leaders have expressed it in the past.

The audience can be characterized by greater consumer costconsciousness, transformation of industries, globalization of markets and greater business uncertainty and risks, sluggish growth and thus a shift of economic power to emerging economics, and rising risks everywhere. Entering onto this world state is a big lesson to be learned by leaders who take notice of the sansdemic change.

\section{SANSDEMIC DROUGHT AND THE DIGITAL DISRUPTORS}

Hyper-Leaders must realize that one of their biggest problems is knowing how to successfully lead in the era of a sansdemic drought. The recent history of talent amounts to a slowmoving tide. After decades of high tide, leaders have become accustomed to being comfortable knowing the talent pool is well stocked. But the tide is going out.

The sansdemic is going to make a tough situation tougher still if we rely on the old relic leadership style and ignore the hyper-leading phenomenon. The point here is primarily to raise awareness, not to provide a silver bullet, for there is none, but there are a few strategies leaders can employ to work with this challenge, even if they cannot immediately eradicate it. Innovation and technology can help fill some of the gaps left by this sansdemic occurring, but to what extent is a matter of ongoing debate [3].

This landscape of hyper-change is not temporary-it is the new norm, creating disequilibrium and disorientation. Why do some firms have success in digital turnaround but majority fail? It's mainly because from a leadership side to make digital transformation of business is a rather complicated process connected with people, skills, company organizational culture and remaking of all business process. There are many obstacles when leading an organization through a digital transformation, but the human side of digital transformation is the most complicated one because it involves a new generation of workers who are entering the stage.

Millennials (born roughly between the years 1980 and 2000) and Generation $\mathrm{Z}$ bring their own values, skills, and mindsets to the leadership mix. Millennials and Generation $Z$ have come of age in the digital era and don't respond well to classic, top-down corporate hierarchies. Instead, they value a more collaborative approach, organic, bottom-up organization. They are motivated by ambitious projects and have a natural affinity for mobile-first and cloud-based collaboration tools, which means this generation can be useful in testing and maximizing the utility of these tools.

New leaders should respond to digital disruption, based on new essential competencies, new work experience and background in the digital age - again enter the hyper-leader. 
Earlier the leader was holding the power in the firm; however, digital times demand leaders to empower others. Organizations have also shifted from having teams collaborating face to face to working in virtual teams. For success in the digital age new successful digital leaders tend to have eclectic backgrounds. Several things are happening at once to transform the world and technological changes are occurring at a head-spinning pace. Technological innovations are the most significant contributors to hyper-change. And these innovations are coming at breathtaking speed. Our brains evolve slowly, but technology changes rapidly. Today, fiveyear-olds spend an average of six hours each day in front of a screen, while teenagers spend an average of nine hours a day consuming digital media. Every day, we write more than 2 million blogs; we generate over 4.5 billion Facebook posts; and we send upward of 23 billion texts. By the time someone reaches 20 , he or she will have been exposed to 30,000 hours of digital information [30]. This has to influence how screenagers think and act.

Who is the leader to lead the screenager generation when they enter the workforce? What are the skills and talents needed in a new emerging hyper-leader? The initial thinking would be to understand that the immersion into the process of digital literacy rewires the brain. Neuroscience has made significant advances in helping us understand how the brain works. Our brains are "plastic and pliable;" they change based on what we see, do, and repeat. New wiring, or synapses, develop. The goal should be to prepare leaders and organizations to deal with these vast changes in technology. We must develop extended minds that help us adjust to hyper-change. How to do this? Aristotle had the answer several thousand years ago: habit. Repeated acts form habits, which over time become part of us. But is that now 'dinosaur thinking' that has become extinct? If hyper-change creates habits, and habits are difficult to break, isn't his thinking quite 'dinosaurish'?

\section{CONCLUSION}

It is vital for the breed of hyper-leaders to pave the way for constructive, intentional changes in individuals and organizations amid the global tsunami of hyper-change. The world is faster, closer, and more connected. Globalization is a process that has been going on for centuries, and what was once a collection of semi-independent sovereign states is morphing into a global village. Today, we are more interdependent and interconnected than ever before, and this connecting process will only accelerate. Globalization is changing the landscape as it brings all its attendant problems and possibilities. Environmental problems are reaching or have reached a tipping point. And demographic changes suggest trouble in countries with aging populations and shrinking workforces. Taken together, this is a potent need for hyper-leadership.

This article hopefully inspires readers to develop new and relevant practices in the field of hyper-leading in the era of hyper-change. Raelin [15] described this field as a 'leadershipas-practice' movement. The essence of the practice is a coordinative effort among people, whether leaders or followers, who choose through their own rules to achieve a distinctive outcome. It also tends to encompass creative problem-solving that are shared within a community. We live in a world of accelerating change, where the future is less and less an extrapolation of the past. Change is unrelenting, pitiless, and occasionally shocking. As Hamel \& Zanini told us, "Welcome to the age of upheaval" [11].

In retrospect, writing in the 16th century, Machiavelli reminds us in The Prince that to be effective, a leader must have virtu (skill), occasione (the right context) and fortuna (luck). Machiavelli alerted us that while skill is important, it is not enough [31]. Thus, the intention for this article was to bring Machiavelli's writing into a hyper-leading era in times of hyper-change. Now let us ask ourselves - do we as leaders today champion the virtues of discontinuity - the growth spurts and the sudden illuminations - or are we still in the Machiavelli era?

\section{REFERENCES}

[1] Heifetz, R. \& Linsky. M. (2017). Leadership on the Line. Boston, MASS; Harvard Business Review Press.

[2] Craig, R. (2015). College Disrupted. New York, NY: Palgrave MacMillan Trade.

[3] Hetrick, R., Grieser, H., Sentz, R., Coffey, C \& Burrow. G. (2021). Demographic Drought. EMSI: Labor Market Analytics. Moscow.

[4] Freska, A., Claus, L. (2013). The new global context: is the world really flat? Global HR Practitioner Handbook, 1, 5-15.

[5] Claus, L. (2019). HR disruption-Time already to reinvent talent management. BRQ Business Research Quarterly, 22, 207-215.

[6] Brown, B. (2018). Dare to Lead. New York, NY: Random House.

[7] Iger, R. (2019). The Ride of a Lifetime: Lessons learned as CEO of the Walt Disney Company. New York, NY: Random House.

[8] Bledsoe, T.S. \& Setterlund, K.A. (2021). Using Narratives and Storytelling to Promote Cultural Diversity on College Campuses. Hershey, PA: IGI Global Publishing.

[9] Buber, M. (1958). I and Thou. New York: Scribner.

[10] Tolle, E. (1997). The Power of Now. Vancouver, Canada: Namaste Publishing.

[11] Hamel, G., \& Zanini, M. (2020). Humanocracy. Boston, Mass: Harvard Business School Publishing.

[12] Hardiman, M. (2012). Brain-Targeted Teaching Model. Thousand Oaks, Cal: Corwin Publishing.

[13] Gardner, H. (1993). Creating Minds. New York, NY: Perseus Books.

[14] Herman, D. (2013). Storytelling and the Sciences of Mind. Cambridge, Mass: The MIT Press.

[15] Raelin, J.A. (2016). Leadership-as-Practice. New York, NY: Routledge Publishing.

[16] Miller, M. (2015). Chess not Checkers: Elevate your Leadership Game. Oakland, Cal: Berrett-Koehler Publishers.

[17] Dweck, C.S. (2016). Mindset: The New Psychology of Success. New York, NY: Random House. 
[18] The Global Risk Report. (2017). World Economic Forum Risk Perception surveys, 2016

[19] Hess, E.D. (2020). Hyper-Learning: How to Adapt to the Speed of Change. Oakland, Cal: Berrett-Koehler Publishers.

[20] Kotter, J.P. (2002). The Heart of Change. Boston, Mass: Harvard Business School Publishing.

[21] Smith, L. (2003). Leadership: The Intrapreneurial experience at the University of Oxford and the University of Warwick, United Kingdom. Doctorate Dissertation, Florida Atlantic University, Boca Raton, Florida.

[22] Collins, J. (2001). Good to Great: Why Some Companies Make the Leap and Others Don't. New York, NY. HarperCollins.

[23] Sowick, M. (Ed.). (2015). Leadership 2050. Bingley, UK: Emerald Group Publishing.

[24] Siang, T.Y. (n.d.). What is Design Thinking? Interaction Design Foundation.

[25] Kolko, J. (2015). Design thinking coming of age: the approach once used primarily in product design, is now infusing corporate culture. Harvard Bus. Rev., 93(9), 66-69.

[26] Martin, R. (2009). The Design of Business: Why Design Thinking is the Next Competitive Advantage. Harvard Business Review Press, Boston.
[27] Bersin, J., Solow, M., Wakefield, N. (2016). Design Thinking: Crafting the Employee Experience.

[28] Palus, C.J., \& Horth, D.M. (2002). The Leader's Edge. San Francisco, Cal: Jossey-Bass.

[29] Bates, M.C. (2010). Composing a Further Life. New York, NY: Random House.

[30] Stonehouse, George H. (2019). Management Challenges in the Age of Digital Disruption. Advances in Economics, Business and Management Research, (v.119) 1st International Conference on Emerging Trends and Challenges in the Management Theory and Practice (ETCMTP 2019). United Kingdom. Atlantis Press.

[31] Mansfield, H. (1998). The Prince. Chicago, Ill: University of Chicago Press.

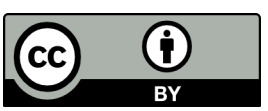

(C) 2021 by the Dr. Linda Ellington. Submitted for possible open access publication under the terms and conditions of the Creative $\left.\begin{array}{llll}\text { Commons Attribution } & (\mathrm{CC} & \mathrm{BY}\end{array}\right)$ license (http://creativecommons.org/licenses/by/4.0/). 